\title{
Implementasi Algoritma Zhu Takaoka Pada Aplikasi Olshop Kamera Digital
}

\author{
Sri Sugiarti, Berto Nadeak \\ Teknik Informatika, STMIK Budi Darma, Medan, Indonesia \\ Email: srisugiarti13@gmail.com \\ Submitted 15-05-2020; Accepted 01-06-2020; Published 14-06-2020
}

\begin{abstract}
Abstrak
Sebuah brand dapat mencerminkan suatu produk, tetapi juga mempunyai dimensi lain yang mampu membedakannya dari produk yang lain dan didesain untuk memenuhi kebutuhan yang sama. Kamera digital adalah alat untuk membuat gambar dari objek untuk selanjutnya dibiaskan melalui lensa pada sensor CCD dan akhir-akhir ini pada sensor BSI-CMOS (Back Side Illuminated) sensor yang lebih irit daya untuk kamera yang lebih canggih yang hasilnya kemudian direkam dalam format digital ke dalam media simpan digital. Perkembangan zaman saat seseorang lebih sering mengabadikan perjalanan hidupnya dengan mengekspresikan setiap kegiatan menjadi sebuah photo menggunakan kamera digital karena dengan hal tersebut proses dapat dilakukan dengan mudah dan hasil yang bagus untuk sebuah photo yang dapat mengabadikan perjalanan hidup seseorang. Dengan bertambahnya waktu pengguna kamera digital semakin bertambah banyak dan brand kamera digital juga semakin bertambah banyak dijual di pasar seperti mall ataupun toko, namun untuk pergi ke mall ataupun toko akan membutuhkan biaya transportasi dan tidak semua orang memiliki waktu kosong untuk melihat brand kamera digital yang baru ke mall ataupun toko dikarenakan banyak nya aktivitas pekerjaan maupun hal lainnya.Untuk mengatasi permasalahan tersebut penulis membangun sebuah Aplikasi yaitu Implementasi Algoritma Zhu-Takaoka Pada Aplikasi Olshop Kamera Digital. Algoritma zhu-takaoka merupakan salah satu algoritma string matching yang dapat melakukan pencarian kata dengan pergeseran karakter menggunakan array 2 (dua) dimensi. Proses inti pencarian algoritma zhu-takaoka yaitu melakukan pencarian kata dengan teknik Right-to-left scan rule. Setiap pergeseran pada proses pencarian kata tentukan dari nilai pergeseran yang ada pada tabel Good Suffix Shift Rule dan Bad-Charcter Shift Rule. Adapun hasil yang diharapkan dari penelitian ini yaitu dapat membantu seseorang yang ingin memiliki kamera digital melihat atau mencari brand kamera digital menggunakan aplikasi android sehingga dapat dilakukan dimanapun tanpa harus pergi ke mall ataupun toko.
\end{abstract}

Kata Kunci: Brand, Kamera Digital, Algoritma, String Matching, Zhu Takaoka, Android.

\begin{abstract}
A brand can reflect a product, but also has another dimension that is able to distinguish it from other products and is designed to meet the same needs. Digital cameras are devices for making images of objects for refraction through lenses on CCD sensors and more recently on BSI-CMOS (Back Side Illuminated) sensors that are more power efficient for more sophisticated cameras whose results are then recorded in digital format to in digital save media. The development of an era when someone more often captures his life's journey by expressing every activity into a photo using a digital camera because with that process can be done easily and good results for a photo that can capture the journey of one's life. With the increasing time of digital camera users more and more and digital camera brands are also increasingly sold in markets such as malls or shops, but to go to malls or shops will require transportation costs and not everyone has a free time to see new digital camera brands to the mall or shop because of its many work activities and other things. To overcome these problems the author builds an application that is the Implementation of the Zhu-Takaoka Algorithm in the Digital Camera Olshop Application. The zhu-takaoka algorithm is a string matching algorithm that can search words by shifting characters using 2 (two) dimensional arrays. The core process of searching for the zhu-takaoka algorithm is to search for words using the Right-to-left scan rule technique. Each shift in the word search process is determined by the shift values in the Good Suffix Shift Rule and Bad-Charcter Shift Rule tables. The expected results of this research are that it can help someone who wants to have a digital camera see or search for a digital camera brand using an Android application so that it can be done anywhere without having to go to the mall or shop.
\end{abstract}

Keywords: Brand, Digital Camera, Algorithm, String Matching, Zhu Takaoka, Android..

\section{PENDAHULUAN}

Brand merupakan nama, istilah, tanda, simbol, desain, atau kombinasi dari semua itu yang dapat digunakan untuk mengenali produk dan service dari penjual dan untuk membedakan produk atau service tersebut dari yang lain. Sebuah brand dapat mencerminkan suatu produk, tetapi juga mempunyai dimensi lain yang mampu membedakannya dari produk yang lain dan didesain untuk memenuhi kebutuhan yang sama. Olshop (Online Shop) atau belanja via internet adalah suatu proses pembelian barang atau jasa dari mereka yang menjual melalui internet, atau layanan jual-beli secara online tanpa harus bertatap muka dengan penjual atau pembeli secara langsung. Online Shop bukan hanya sekedar dianggap sebagai pemilihan dalam berbelanja, melainkan telah menjadi bagian dari adanya perubahan sosial budaya dalam masyarakat.Kamera Digital Single Lens Reflex atau biasa disebut dengan kamera digital adalah kamera yang menggunakan sistem jajaran lensa jalur tunggal untuk melewatkan berkas cahaya menuju kedua tempat, yaitu Focal Plane dan View finder, sehingga memungkinkan fotografer untuk melihat objek melalui kamera yang sama persis seperti hasil fotonya. Seiring berkembangnya kamera pada era globalisasi sekarang ini, penerapan teknologi sangat dibutuhkan demi mendapatkan kriteria yang sesuai dengan kebutuhan fotografer.

Saat ini pengguna kamera digital semakin bertambah banyak dikarenakan saat ini kamera digital banyak digunakan untuk mengabadikan perjalanan hidup dengan mengekspresikan setiap kegiatan menjadi sebuah photo sehingga banyak brand kamera digital bersaing agar lebih diminati di masyarakat. Hal membuat pengusaha di bidang dagang kamera digital harus mengikuti perkembangan teknologi dalam hal pemasaran kamera digital, yaitu penyampaian informasi mengenai brand kamera digital yang dijual kepada calon pelanggan terutama calon pelanggan yang memiliki banyak aktivitas. Namun dikarenakan jumlah brand kamera digital yang banyak dapat menimbulkan permasalahan dalam prosedur pencarian brand 
kamera digital, oleh sebab itu diperlukan penerapan algoritma string matching untuk mempermudah dalam proses pencarian tersebut.

Untuk mengatasi permasalahan yang telah diuraikan diatas penulis membangun aplikasi kamera olshop berbasis android menggunakan editor eclipse juno dan menerapkan algoritma zhu-takaoka untuk pencarian brand kamera digital. Algoritma zhu-takaoka merupakan salah satu algoritma string matching yang dapat melakukan pencarian kata dengan pergeseran karakter menggunakan array 2 (dua) dimensi. Proses inti pencarian algoritma zhu-takaoka yaitu melakukan pencarian kata dengan teknik Right-to-left scan rule. Setiap pergeseran pada proses pencarian kata tentukan dari nilai pergeseran yang ada pada tabel Good Suffix Shift Rule dan Bad-Charcter Shift Rule [1].

\section{METODE PENELITIAN}

\subsection{String Matching}

String Matching adalah proses pencarian semua kemunculan query yang selanjutnya disebut pattern ke dalam string yang lebih panjang atau teksKedua string terdiri dari sekumpulan karakter yang disebut alfabet yang dilambangkan dengan $\sum$ (sigma) dan mempunyai ukuran $\sigma$ (tao). String matching dibagi menjadi dua, yakni exact matching dan heuristic atau statistical matching. Exact Matching digunakan untuk menemukan pattern yang berasal dari satu teks [2].

\subsection{Zhu-Takaoka}

Algoritma BM" (Algoritma Zhu-Takaoka) yang merupakan modifikasi dari Algoritma Boyer-Moore mempunyai ciri-ciri yang sama dalam proses pencarian string. Ciri-ciri tersebut yaitu terbagi dua fase yaitu fase reprocessing dan fase pencarian. Perbedaan antara Algoritma Boyer-Moore dan Algoritma Zhu-Takaoka yaitu terletak pada tahap penentuan bad character rule.Dalam Boyer-Moore, bad character hanya terdiri array satu dimensi, sedangkan dalam Zhu-Takaoka dimodifikasi menjadi array dua dimensi. Teknik ini membandingkan pattern yang dicari dengan sumber teks dimulai dari kanan ke kiri [1]. Adapun prosedur pencocokan string menggunakan algoritma Zhu-Takaoka adalah sebagai berikut :

1. Pre Zhu-Takaoka Bad Character Table (PreZTBc)

Fungsi dari prosedur preZTBc yaitu untuk menentukan berapa besar pergeseran yang dibutuhkan untuk mencapai karakter tertentu pada pattern dari dua karakter pattern terakhir/terkanan. Hasil dari prosedur preZTBc disimpan pada tabel ZTBC

2. Pre Boyer-Moore Good Suffixes (PreBmGs)

Fungsi dari prosedur suffix yaitu untuk memeriksa kecocokan sejumlah karakter yang dimulai dari karakter terakhir/terkanan dengan sejumlah karakter yang dimulai dari setiap karakter yang lebih kiri dari karakter terkanan tadi. Hasil dari prosedur suffix disimpan pada tabel suff. Jadi suff [i] mencatat panjang dari suffix yang cocok dengan segmen dari pattern yang diakhiri karakter ke-i. Dengan prosedur preBmGs, dapat diketahui berapa banyak langkah pada pattern dari sebeuah segmen ke segmen lain yang sama yang letaknya lebih kiri dengan karakter di sebelah kiri segmen yang berbeda. Prosedur preBmGs menggunakan tabel suff untuk mengetahui semua pasangan segmen yang sama. Hasil dari prosedur preBmGs disimpan pada tabel BmGs.

3. Dilakukan proses pencarian string dengan menggunakan hasil dari prosedur preBmBc dan preBmGs yaitu tabel $B m B c$ dan $B m G s$ [3].

\subsection{Brand}

Kata brand berasal dari kata kuno yaitu brandr yang berarti menyala. Brand masih merupakan sarana supaya pemilik/owner bisa dikenali oleh pihak lain. Menurut Asosiasi Pemasaran Amerika, sebuah brand atau merek merupakan nama, istilah, tanda, simbol, desain, atau kombinasi dari semua itu yang dapat digunakan untuk mengenali produk dan service dari penjual, dan untuk membedakan produk atau service tersebut dari yang lain. Sebuah brand mencerminkan suatu produk, tetapi juga mempunyai dimensi lain yang mampu membedakannya dari produk yang lain dan didesain untuk memenuhi kebutuhan yang sama. Perbedaan ini bisa jadi rasional dan nyata, atau lebih simbolik, emosional, atau tidak berwujud. Oleh karenanya, sebuah produk yang branded atau bermerek bisa jadi adalah berupa produk fisik atau berbentuk fisik [4].

\subsection{Kamera Digital}

Kamera digital merupakan alat untuk membuat gambar dari objek untuk selanjutnya dibiaskan melalui lensa pada sensor $C C D$ dan akhir-akhir ini pada sensor BSI-CMOS (Back Side Illuminated) sensor yang lebih irit daya untuk kamera yang lebih canggih yang hasilnya kemudian direkam dalam format digital ke dalam media simpan digital. Kemudahan dari kamera digital adalah hasil gambar yang dengan cepat diketahui hasilnya secara instan dan kemudahan memindahkan hasil (transfer). Beberapa kamera digital, terutama DSLR(Digital Single Lens Reflex) dan high-end cameras dilengkapi fasilitas $R A W$ yang dapat ditindaklanjuti di komputer mengunakan perangkat lunak tertentu untuk hasil terbaik, tetapi pada saat ini fasilitas Auto Mode telah menghasilkan gambar yang baik dalam format JPEG (Joint Photographic Expert Group)[5].

\section{HASIL DAN PEMBAHASAN}

Pada perkembangan zaman saat ini penggunaan kamera digital single lens reflex atau biasa disebut dengan kamera digital semakin dibutuhkan untuk mendapatkan kriteria photo yang sesuai dengan kebutuhan demi mengabadikan perjalanan 
hidupnya dengan mengekspresikan setiap kegiatan menjadi sebuah photo menggunakan kamera digital. Dengan bertambahnya waktu pengguna kamera digital semakin bertambah banyak dan brand kamera digital juga semakin bertambah banyak dijual di pasar seperti mall ataupun toko, namun untuk pergi atau berkunjung langsung ke mall atau toko penjualan kamera digital akan membutuhkan biaya transportasi dan tidak semua orang memiliki waktu kosong untuk melihat brand kamera digital yang baru ke mall ataupun toko dikarenakan banyaknya aktivitas pekerjaan maupun hal lainnya.

Aplikasi kamera olshop berbasis android yang penulis rancang dan menerapkan algoritma Zhu-Takaoka pada fitur pencarian brand kamera digital dinilai dapat mempermudah proses untuk mendapatkan hasil pencarian brand kamera digital untuk dibeli dengan waktu yang efektif dan efesien tanpa harus berkunjung langsung ke mall atau toko penjual kamera digital yang menyediakan sesuai dengan keinginan pembeli.

Algoritma Zhu Takaoka merupakan salah satu algoritma string matching yang dapat melakukan pencarian kata dengan pergeseran karakter menggunakan array 2 (dua) dimensi. Proses inti pencarian algoritma Zhu-Takaoka yaitu melakukan pencarian kata dengan teknik Right-to-left scan rule. Setiap pergeseran pada proses pencarian kata tentukan dari nilai pergeseran yang ada pada tabel Good Suffix Shift Rule dan Bad-Charcter Shift Rule.

Beberapa brand kamera digital menjadi contoh pada penelitian ini adalah sebagai berikut :

Tabel 1. Brand Kamera Digital

\begin{tabular}{|c|c|c|}
\hline No & Cari Brand / Merk & Detail Produk Kamera \\
\hline 1 & $\begin{array}{l}\text { Sony Cybershot } \\
\text { DSC-H300 }\end{array}$ & $\begin{array}{l}\text { Type kamera Kompak, Optical Zoom 35x, Tipe Baterai AA Battery, Valid Vixel Approx. } \\
\text { 20.1MP, Rp 2.160.000 }\end{array}$ \\
\hline 2 & CANON Eos m50 & $\begin{array}{l}\text { 24.1MP APS-C CMOS Sensor, DIGIC } 8 \text { Image Processor, 2.36m-Dot OLED Electronic } \\
\text { Viewfinder, 9.000.000 }\end{array}$ \\
\hline 3 & $\begin{array}{l}\text { NIKON D3400 } 18- \\
55 \text { KIT VR }\end{array}$ & $\begin{array}{l}\text { 24.2MP DX-Format CMOS Sensor, EXPEED } 4 \text { Image Processor, Native ISO 100-25600; } 5 \\
\text { fps Shooting, } 6.000 .000\end{array}$ \\
\hline 4 & $\begin{array}{l}\text { Camdig SAMSUNG } \\
\text { WB-80OF }\end{array}$ & Resolusi $16.3 \mathrm{MP}$, Optical 21 x, Memory SD/SDHC/SDXC, 3.000.000 \\
\hline 5 & $\begin{array}{l}\text { Sony Cybershot } \\
\text { DSC-W810 }\end{array}$ & $\begin{array}{l}\text { Type kamera Kompak, Optical Zoom 6x, Resolusi 1280x720, Valid Vixel Approx. } 20.1 \\
\text { Megapixels, Rp 1.129.000 }\end{array}$ \\
\hline 6 & $\begin{array}{l}\text { Sony Cybershot } \\
\text { DSC-W830 }\end{array}$ & $\begin{array}{l}\text { Type kamera Kompak, Optical Zoom 8x, Resolusi 640x480, Valid Vixel Approx. } 20.1 \\
\text { Megapixels, Rp 1.399.000 }\end{array}$ \\
\hline 7 & $\begin{array}{l}\text { Sony Cybershot } \\
\text { DSC-RX100 VI }\end{array}$ & $\begin{array}{l}\text { Type kamera Kompak, Optical Zoom 8x, Resolusi 640x480, Valid Vixel Approx. } 20.1 \\
\text { Megapixels, Rp 1.399.000 }\end{array}$ \\
\hline 8 & $\begin{array}{l}\text { NIKON COOLPIX } \\
P 900\end{array}$ & $\begin{array}{l}\text { Type kamera Kompak, Optical Zoom 83x, Resolusi 1920x1080 (Full HD), Valid } \\
\text { Vixell6.Omillion,Tipe Baterai One Rechargeable Li-ion Battery, Rp 7.345.000 }\end{array}$ \\
\hline 9 & $\begin{array}{l}\text { NIKON } \\
\text { L320 }\end{array}$ & $\begin{array}{l}\text { Type kamera Kompak, Optical Zoom 26x, Resolusi 1280x720, Valid Vixel 16.1MP, Tipe } \\
\text { Baterai Four LR6/L4O (AA-size) alkaline batteries, Rp 1.750.000 }\end{array}$ \\
\hline 10 & $\begin{array}{l}\text { NIKON } \\
\text { D3100 Kit }\end{array}$ & $\begin{array}{l}\text { Type kamera DSLR - dengan Lens, Optical Zoom 26x, Resolusi } 1280 x 720 \text {, Valid Vixel } \\
\text { 14.2MP,Tipe Baterai Four LR6/L4O (AA-size) alkaline batteries, Rp } 6.195 .000\end{array}$ \\
\hline
\end{tabular}

Pada penelitian ini penulis melakukan penyelesaian masalah pencarian brand kamera digital dengan menerapkan algoritma Zhu-Takaoka pada aplikasi kamera olshop berbasis android yang akan dirancang. Pada contoh kasus pencarian brand kamera digital penulis menggunakan Kata "SONY" sebagai pattern dan Kata "DISCOUNT SONY" sebagai text. Langkah pertama yang dilakukan adalah menciptakan dua buah tabel shif atau pergesaran ZtBc (Zhu-Takaoka Bad Character) dan bmGs (Boyer-Moore Good Suffixes).

Tabel 2. ZtBc (Zhu-Takaoka Bad Character Table)

\begin{tabular}{cccccc}
\hline $\boldsymbol{Z} \boldsymbol{t B \boldsymbol { c }}$ & $\mathbf{N}$ & $\mathbf{O}$ & $\mathbf{S}$ & $\mathbf{Y}$ & $*$ \\
\hline $\mathbf{N}$ & 3 & 2 & 4 & 4 & 4 \\
$\mathbf{O}$ & 3 & 3 & 1 & 4 & 4 \\
$\mathbf{S}$ & 3 & 2 & 4 & 4 & 4 \\
$\mathbf{Y}$ & 3 & 4 & 4 & 4 & 4 \\
$*$ & 3 & 4 & 4 & 4 & 4 \\
\hline
\end{tabular}

Tabel ZtBc berbentuk array dua dimensi yang baris dan kolomnya diisi berdasarkan pada pattern yang akan dicari. Tabel $Z t B c$ adalah hasil modifikasi dari algoritma boyer moore yang hanya memiliki bentuk array datu dimensi yaitu tabel Boyer-Moore Good Suffixes. Tanda * pada tabel $Z t B c$ berfungsi untuk mewakili setiap karakter yang tidak terdapat pada pattern yang akan dicari.

Tabel 3. Boyer-Moore Good Suffixes

\begin{tabular}{lllcc}
\hline $\boldsymbol{I}$ & 0 & 1 & 2 & 3 \\
$\boldsymbol{x}[\boldsymbol{i}]$ & $\mathrm{S}$ & $\mathrm{O}$ & $\mathrm{N}$ & $\mathrm{Y}$ \\
suff $[\boldsymbol{i}]$ & 0 & 0 & 0 & 4 \\
bmGs $[\boldsymbol{i}]$ & 4 & 4 & 3 & 1 \\
\hline
\end{tabular}


Setelah menciptakan tabel ZtBc dan tabel bmGs tahapan selanjutnya yaitu melakukan pencocokan pattern dan teks dengan menggunakan teknik pencarian right-to-left scan rule. Langkah-langkah yang dilakukan dalam proses pencocokan pattern "SONY" dengan text "DISCOUNT SONY" menggunakan algoritma zhu-takaoka adalah sebagai berikut ini :

Langkah ke- 1

Tabel 4. Langkah Ke-1

\begin{tabular}{|c|c|c|c|c|c|c|c|c|c|c|c|c|}
\hline window & & & $*$ & $*$ & & & & & & & & \\
\hline Text & D & I & S & $\mathrm{C}$ & $\mathrm{O}$ & $\mathrm{U}$ & $\mathrm{N}$ & $\mathrm{T}$ & $S$ & $\mathrm{O}$ & $\mathrm{N}$ & Y \\
\hline Pattern & $\mathrm{S}$ & $\mathrm{O}$ & $\mathrm{N}$ & $\mathrm{Y}$ & & & & & & & & \\
\hline I & 0 & 1 & 2 & 3 & & & & & & & & \\
\hline
\end{tabular}

Pada langkah ke-1 tidak ditemukan kecocokan antara pattern dan text yang ada pada karakter (D \& S), (I \& O), (S \& N), dan (C \& Y). Maka dilakukan pergeseran berdasarkan nilai $Z t b c\left[{ }^{*}\right]\left[{ }^{*}\right]=4$ atau $B m g s[0]=4$.

Langkah ke- 2

Tabel 5. Langkah Ke-2

\begin{tabular}{llllllllllllll}
\hline window & & & & & & & $\mathrm{N}$ & & & & & & \\
Text & $\mathrm{D}$ & $\mathrm{I}$ & $\mathrm{S}$ & $\mathrm{C}$ & $\mathrm{O}$ & $\mathrm{U}$ & $\mathrm{N}$ & $\mathrm{T}$ & & $\mathrm{S}$ & $\mathrm{O}$ & $\mathrm{N}$ & $\mathrm{Y}$ \\
Pattern & & & & & $\mathrm{S}$ & $\mathrm{O}$ & $\mathrm{N}$ & $\mathrm{Y}$ & & & & & \\
$\mathrm{I}$ & & & & & 0 & 1 & 2 & 3 & & & & & \\
\hline
\end{tabular}

Pada langkah ke-2 ditemukan kecocokan antara pattern dan text yang ada pada karakter (N \& N). Maka dilakukan pergeseran berdasarkan nilai $Z t b c[\mathrm{~N}][\mathrm{N}]=3$ atau $B m g s[1]=3$.

Langkah Ke-3

Tabel 5. Langkah ke- 3

\begin{tabular}{lllllllllllllll}
\hline window & & & & & & & & & S & O & & \\
Text & $\mathrm{D}$ & $\mathrm{I}$ & $\mathrm{S}$ & $\mathrm{C}$ & $\mathrm{O}$ & $\mathrm{U}$ & $\mathrm{N}$ & $\mathrm{T}$ & & $\mathrm{S}$ & $\mathrm{O}$ & $\mathrm{N}$ & $\mathrm{Y}$ \\
Pattern & & & & & & & & $\mathrm{S}$ & $\mathrm{O}$ & $\mathrm{N}$ & $\mathrm{Y}$ & & \\
$\mathrm{I}$ & & & & & & & & 0 & 1 & 2 & 3 & & \\
\hline
\end{tabular}

Pada langkah ke-3 tidak ditemukan kecocokan antara pattern dan text yang ada pada karakter (T \& S), ( \& O), (S \& N), dan (O \& Y). Maka dilakukan pergeseran berdasarkan nilai $Z t b c[\mathrm{~S}][\mathrm{O}]=2$ atau $B m g s[3]=2$.

Langkah Ke -4

Tabel 6. Langkah ke- 4

\begin{tabular}{lllllllllllllll}
\hline window & & & & & & & & & & & & & & \\
Text & D & I & S & C & O & U & N & T & & S & O & N & Y \\
Pattern & & & & & & & & & & S & O & N & Y \\
I & & & & & & & & & & 0 & 1 & 2 & 3 \\
\hline
\end{tabular}

Pada langkah ke-4 semua karakter pada pattern memiliki kecocokan dengan karakter pada text yaitu (S \& S), (O \& O), (N $\& \mathrm{~N})$, dan ( $\mathrm{Y} \& \mathrm{Y}$ ) maka proses pencocokan karakter diberhentikan.

\subsection{Implementasi}

1. Halaman Menu Utama

Adapun screenshoot gambar untuk tampilan menu utama pada aplikasi kamera olshop berbasis android yang dibangun oleh penulis pada penelitian ini dapat dilihat pada gambar berikut :

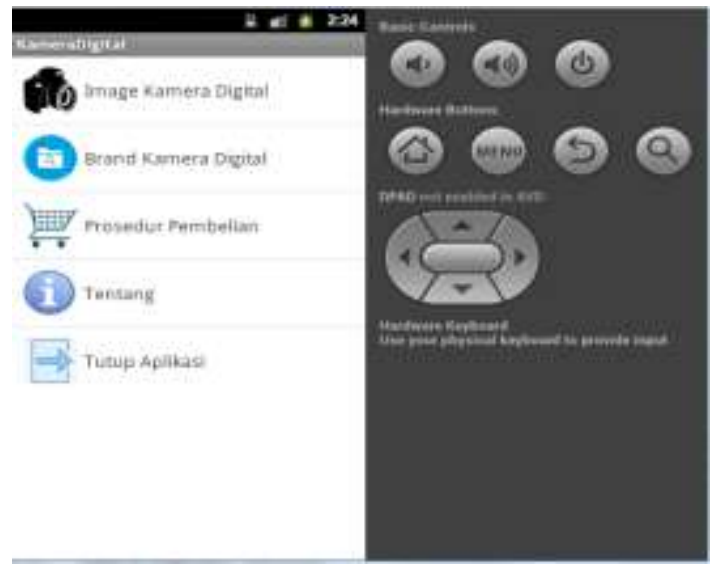

Gambar 1. Halaman Menu Utama 
2. Halaman Image Kamera Digital

Adapun screenshoot gambar untuk halaman image kamera digital pada aplikasi kamera olshop berbasis android dapat dilihat pada gambar berikut :

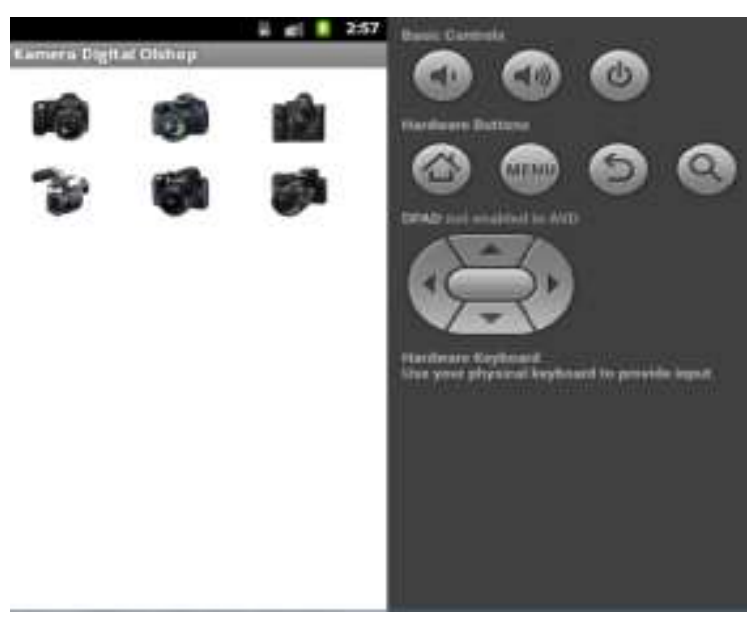

Gambar 2. Halaman Image Kamera Digital

3. Halaman Brand Kamera Digital

Adapun screenshoot gambar untuk halaman brand kamera digital pada penelitian ini dapat dilihat pada gambar berikut

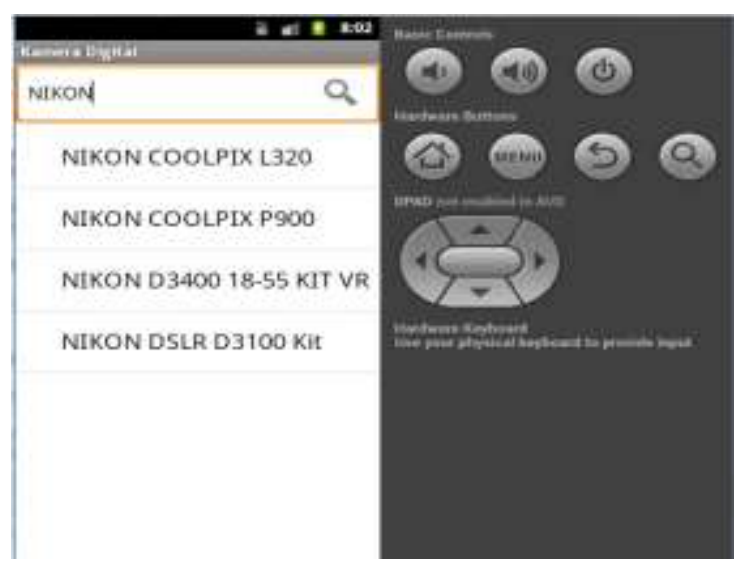

Gambar 3. Halaman Brand Kamera Digital

4. Halaman Hasil Pencarian Detail Kamera Digital

Adapun screenshoot gambar untuk halaman hasil pencarian detail kamera digital pada penelitian ini dapat dilihat pada gambar berikut :

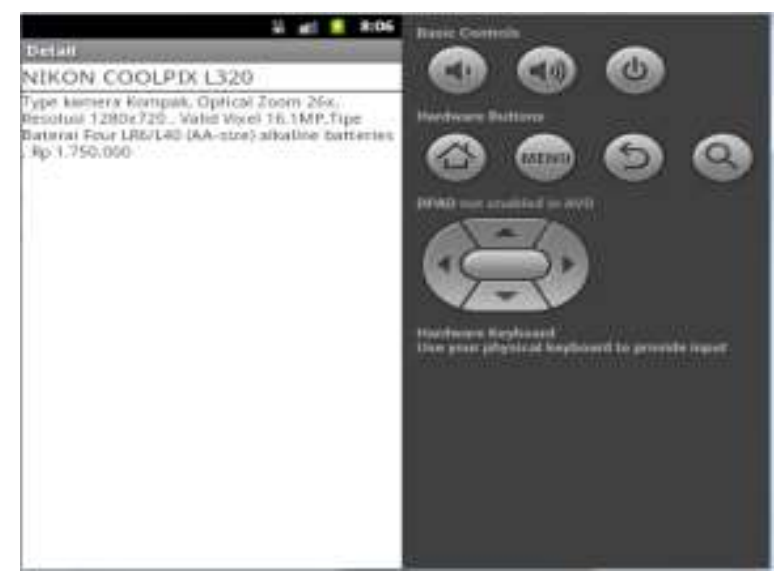

Gambar 4. Halaman Hasil Pencarian Detail Kamera Digital

5. Halaman Prosedur Pembelian

Adapun screenshoot gambar untuk halaman prosedur pembelian kamera digital pada penelitian ini dapat dilihat pada gambar berikut : 


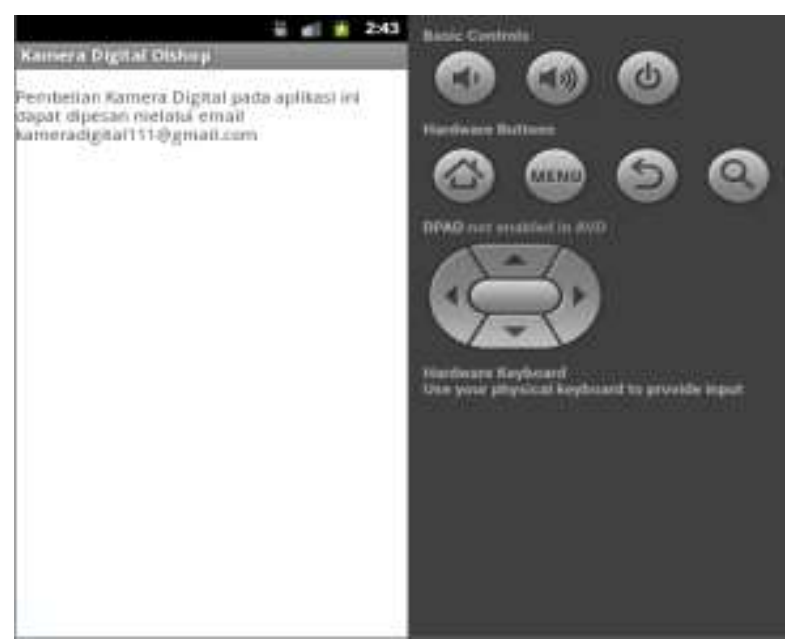

Gambar 5. Halaman Prosedur Pembelian

\section{KESIMPULAN}

Adapun kesimpulan yang dapat diuraikan oleh penulis berdasarkan hasil penelitian ini adalah sebagai berikut ini :

1. Pencarian informasi produk kamera digital dilakukan berdasarkan brand atau merk kamera digital.

2. Penerapan algoritma zhu-takaoka pada aplikasi kamera olshop berbasis android dapat mempermudah proses pencarian informasi produk kamera digital dilakukan berdasarkan brand atau merk kamera digital.

3. Aplikasi kamera olshop berbasis android pada penelitian ini dibangun menggunakan editor eclipse juno.

\section{REFERENCES}

[1] Jos Timanta Tarigan Efelin O Siburian M. Andri Budiman, Implementasi Dan Perbandingan Algoritma Berry-Ravindran Dan Algoritma Zhu-Takaoka Pada Aplikasi Kamus Bahasa Indonesia-Batak Toba. Medan: Universitas Sumatera, 2016.

[2] http://www.gurupendidikan.co.id/9-pengertian-implementasi-menurut-para-ahli/,.

[3] M. \& Handrizal Zarlis, Algoritma \& Pemrograman : Teori dan Pratik dalam Pascal. Medan: USU PRESS, 2008.

[4] https://marketing.co.id/kevin-keller-apa-itu-merek-kenapa-merek-itu-penting-1/,.

[5] https://id.wikipedia.org/wiki/Kamera_digital,.

[6] https://www.neliti.com/publications/118440/pengaruh-instagram-sebagai-media-online-shopping-fashion-terhadap-perilaku-konsu 